\title{
Education in Ukraine and Covid-19: New Perspectives and Opportunities
}

\author{
Iryna Shtuler ${ }^{1 *}$, Tatiana Suhak ${ }^{2}$ \\ ${ }^{1}$ Faculty of Economic, National Academy of Management, Kyiv, 03151, Ukraine \\ ${ }^{2}$ Faculty of Economic, National Academy of Management, Kyiv, 03151, Ukraine \\ *Corresponding Author: obl2@nam.kiev.ua
}

Copyright $\odot 2020$ by authors, all rights reserved. Authors agree that this article remains permanently open access under the terms of the Creative Commons Attribution License 4.0 International License

Article History: Received: 10 November 2020; Revised 12 January 2021; Accepted: 27 January 2021; Published online: 5 April 2021

Abstract Officially, the COVID-19 pandemic reached Ukraine in March 2020 and came to Ukraine at a time when the national economy was not in the best condition. In fact, the COVID-19 pandemic has transformed not only the structure of the national economy, but also the way of doing business. This is evidenced by indicators that reflect changes in the structure of gross domestic product, changes in the structure of employment and marketing tools.

The COVID-19 pandemic has already led to a financial crisis and a crisis in certain areas and sectors of the economy, but there are those who have benefited from quarantine measures. However, there are industries and areas of activity for which the COVID-19 pandemic has given a good start and revenue growth.

Timely response and targeted action will reduce the negative impact of the COVID-19 pandemic, prevent a decline in business activity, create conditions for the development of Ukrainian manufacturers and reduce the impact of the crisis caused by the COVID-19 pandemic.

Keywords Covid-19, Education, pandemic, COVID-19, growth, opportunities

\section{Introduction}

The global economic crisis began to grow in January 2020, over time, more and more countries began to experience a decrease in business activity, the closure of large companies, an increase in the unemployed population, in the end world economy entered the stage of a deep recession. This was facilitated by the closure of the borders of many countries of the world and traffic restrictions, the introduction of strict quarantine measures. The world community directed all actions to save human lives and reduce the spread of the epidemic, and the economy froze in anticipation of events. No one was prepared for a protracted crisis and large economic losses in all sectors of the economy, the consequences of which some countries will experience for many years to come.

The purpose of the article is to determine to what extent the COVID-19 pandemic has 
affected the economy of Ukraine as a whole and separately to industries, create on the basis of this study a concept for Ukraine's exit from the economic crisis.

\section{Materials and Methods}

The theoretical basis of the article were the key provisions of modern economic theory and modern concepts of innovative development at the global and macro levels, highlighted in the scientific works of the world's leading scientists. The methods of theoretical modeling, systematization, grouping, logical generalization, structural-logical analysis were also used in the work.

\section{Result and Discussion}

According to the World Bank, the economic activity of business in the spring of 2020 decreased by $7 \%$, and the projected reduction in world GDP is expected to be 5,2\%, but this is an optimistic forecast and if the outbreaks of COVID-19 continue to increase in the future, the projected decrease in GDP is expected to reach $8 \%$ [1]. The economies of developed countries will overcome the crisis faster by supporting small and medium-sized businesses, reducing lending rates, providing subsidies to sectors of the economy with large losses, as well as financially supporting the citizens of their country. The economies of developing countries may fall into a protracted recession, where the number of unemployed increases, small and medium-sized businesses suffer losses, the income level of the population decreases and leads to extreme poverty, according to a critically reduced consumer demand and the level of GDP.

The first effects of the economic crisis were felt in China, from which the COVID-19 epidemic began, for the 1st quarter of 2020 the GDP level decreased by $6,8 \%$ compared to last year, which amounted to 98 billion USD. The economic consequences were caused by the halt of industrial production, the closure of borders and the impossibility of exporting their own goods, which affected the global economy and companies dependent on Chinese goods. Among them are such well-known companies: Apple, Tesla, Facebook, Microsoft, Hyundai, Nissan also suspended their activities during the quarantine. Even the market for medical drugs shrank and suffered losses due to a shortage of drugs exported to the United States from China. Industrial production fell by 13,5\%, the largest drop in production over the past 30 years. During the 1st quarter of 2020, the unemployment rate also increased and per capita income decreased by $4 \%$ compared to the previous year, which leads to a drop in consumer demand by $12,5 \%$ [3]. At the same time, the COVID-19 pandemic contributed to the development of the express delivery sector, the growth index of which was $75 \%$ from last year, the index is compiled according to the development of courier services and logistics companies [2]. The Chinese government has developed a series of measures to revitalize the economy after the crisis. These are: an increase in investments in infrastructure and real estate, support for small and medium-sized businesses, support for monetary, fiscal and financial policies, an increase in jobs and an increase in the standard of living of the population. According to IMF forecasts, China will quickly restore its economy and may even be able to get a GDP growth of 1,0\% in 2020 (see Table 1). 
Table 1. Forecast of GDP change for the world economy for 2020-2021

\begin{tabular}{|l|l|l|l|}
\hline Economies of countries & $\mathbf{2 0 1 9}$ & $\mathbf{2 0 2 0}$ & $\mathbf{2 0 2 1}$ \\
\hline World Output & 2,9 & $-5,2$ & 5,4 \\
\hline United States & 2,3 & $-8,0$ & 4,5 \\
\hline China & 6,1 & 1,0 & 8,2 \\
\hline Germany & 0,6 & $-7,8$ & 5,4 \\
\hline France & 1,5 & $-12,5$ & 7,3 \\
\hline Italy & 0,3 & $-8,3$ & 4,6 \\
\hline Spain & 2,0 & $-12,8$ & 6,3 \\
\hline Japan & 0,7 & $-5,8$ & 2,4 \\
\hline United Kingdom & 1,4 & $-10,2$ & 6,3 \\
\hline India & 4,2 & $-4,5$ & 6,0 \\
\hline Russia & 1,3 & $-6,6$ & 4,1 \\
\hline Ukraine & 3,2 & $-8,2$ & 1,1 \\
\hline Brazil & 1,1 & $-9,1$ & 3,6 \\
\hline The COVID-19 & . & \\
\hline
\end{tabular}

The COVID-19 epidemic has not spared the United States, economy of which has suffered heavy losses. Experts call this crisis more than the financial crisis in the United States in 2008-2009. Since the beginning of the epidemic, a number of negative events have taken place in the United States that directly affected the entire economy of the country. In March, a record low drop in oil prices took place, at some point the price of oil became negative for the first time in history. This is due to a decline in business activity, travel and air travel bans, which resulted in a 30\% drop in global oil demand. Spring 2020 in the US stock market will go down in history as the most crisis and panic period. In a short time, the American Dow Jones stock index fell to 9,99\% in early March, which was the biggest drop since 1987. At the end of March, it rose to $21 \%$, which compares with the largest three-day growth since 1931 [5]. In April 2020, the number of unemployed in the United States was $14,7 \%$, per capita income fell by $10 \%$ compared to last year. The number of applications since the beginning of the year for unemployment benefits that were submitted under traditional and pandemic programs amounted to 33 million, that is, so many people became unemployed [3]. The consequences of the Covid-19 pandemic will be colossal for the entire US economy, the results already obtained for the 2nd quarter of 2020. The economic activity of the population has decreased, many companies are going bankrupt. To stabilize the situation in the United States and help the population, the Government of the country paid an unemployment benefit of 600 USD per week for workers who lost their jobs during the pandemic. This aid helped to boost consumer demand. According to IMF forecasts, given the increase in the number of patients and the introduction of quarantine measures by the end of the year, GDP will fall by $8 \%$.

The COVID-19 pandemic has had a huge impact on the Italian economy. During the quarantine, the entire industry stopped, a ban on movement, a stop of all air travel, a ban on the entry of tourists, this is $13 \%$ of GDP and about 1,7 million people employed in this industry. According to economists, for the 1 st quarter of 2020, GDP decreased by $4,7 \%$, the level of industrial production was $-20,3 \%$, and the unemployment rate was $8,4 \%$. In Italy, during the 
COVID-19 Pandemic, inequality between different social strata of the population has significantly worsened. The Italian government has allocated funds to support medicine, payments to citizens, regulate credit issues and help businesses.

Having considered the experience of other countries in overcoming the economic crisis and supporting small and medium-sized businesses, it is important to learn the best practices that can be adapted for the Ukrainian economy. Various spheres of life require close approach, analysis and support. During the COVID-19 pandemic, first of all, health systems are checked for orderliness, mobility and the rapid response of state support for medicine and protecting the health and life of the country's population. For the economy, it is important to support small and medium-sized businesses, the settlement of credit issues. The population of the country expects help and protection in the state, these are material payments that can support consumer demand.

Officially, the COVID-19 pandemic reached Ukraine in March 2020 and came to Ukraine at a time when the national economy was no longer in the best condition. In fact, the COVID-19 pandemic has transformed not only the structure of the national economy, but also the way we do business. This is evidenced by indicators that reflect changes in the structure of gross domestic product, changes in the structure of employment and marketing tools. According to statistics for the first quarter of 2020, real GDP decreased by 1,3\%, respectively, compared to the previous quarter of 2019 [6]. The government of the country has formed a reserve fund to support and stimulate the Ukrainian economy in the amount of 60 billion UAH.

The COVID-19 pandemic has already led to a financial crisis and a crisis in certain areas and sectors of the economy, but there are those who have benefited from quarantine measures. Let us consider the impact of COVID-19 on each side.

Industry. According to the Ministry of Economic Development, Trade and Agriculture of Ukraine in January 2020, industrial production decreased by 5,1\%. In February, there was a slight increase in industrial production by $2 \%$, but since March, the introduction of strict quarantine measures and a partial halt in production gave a significant decrease compared to the previous year.

Building. The slight drop in non-residential construction is primarily due to state construction, which is carried out in accordance with the budget approved last year. Also, private investors continue construction in accordance with previously approved budgets and already allocated advance funds. Construction in the residential sector is sharply declining due to the risks of falling effective demand and the opportunity for developers to take a break to save resources. The index of construction products for January-May (relative to the same period last year) $-92,9$, the largest drop occurred in housing construction $-81,7$, least of all in non-residential - 99,8. At the same time, the construction index during the pandemic was: 103,6 in January, in January-February - 99,4, but already in March, after the introduction of quarantine measures, it dropped sharply to 94,5 (for the period January-March). In May, there was an increase in the pace of construction relative to April - by $8,3 \%$.

The number of people employed in construction has not changed significantly, which, together with a reduction in production, means an increase in the load of the wages fund on the cost of production. Partially, the problems with the wage bill may be evidenced by the increase in wage arrears from January 1 to June 1, 2020 by 16,9\%, while almost $71 \%$ of the 
debt falls on economically active enterprises.

Transport. The transport industry has become hostage to quarantine due to the pandemic caused by COVID-19, which significantly limited passenger traffic. That is why the transport of passengers should be considered separately from the transport of goods, since the last pandemic was affected only in the context of a decline in production and trade, including international trade.

In terms of passenger transportation, the March ban on rail transportation and restrictions on transportation and transportation by public transport actually stopped the passenger transportation market for a long time, so it is difficult to assess the industry's losses from the consequences of the pandemic separately from administrative regulation. The overall reduction in the number of passengers carried in January-May 2020 amounted to 43,7\% compared to the same period last year, but these losses are almost entirely explained by quarantine measures. In particular, for a long time passenger rail and air transportation was prohibited, and the movement of public transport was regulated, in addition, there were restrictions on road transportation.

In terms of cargo transportation, the overall decrease in cargo turnover in January-May amounted to $19,9 \%$, while the reduction in cargo turnover by rail, road and water transport averaged about $10 \%$, which correlates with a decrease in industrial production $(-9,7 \%)$. The largest drop occurred in the pipeline transportation sector, but here the indicators directly depend on the volume of transit transportation of energy carriers, which is influenced by factors that are not related or are weakly related to the pandemic in the country and the world.

Logistic services. In contrast to freight transport, there is an increased demand for the delivery of goods ordered online. Services such as Glovo, Raketa, Uber Eats and others face the challenge of delivering everything. The total growth in orders is $20 \%$. The delivery radius has also grown - before it was $2,5 \mathrm{~km}$, now the services of these companies have expanded to $3,5 \mathrm{~km}$.

Agriculture. Agriculture has specific factors of influence on the level of production and sales, therefore, the economic crisis that is unfolding in the world and the country, as well as the COVID-19 pandemic, has little impact on the industry as a whole. However, the quarantine measures introduced by the authorities as a response to the pandemic in Ukraine especially affected the sale of agricultural products by private farms.

The general index of agricultural products sold in January of this year amounted to $111,4 \%$ against the volume of January last year, later the index decreased and in May reached $97,1 \%$ of the volume of January-May 2019. This decrease was due to the sale of crop production, at the same time, the sale of livestock products changed insignificantly and in January-May of this year amounted to $99,2 \%$ of the volume of the same period in 2019.

If we consider the situation in the agricultural sector by producer categories (Diagram 2), we will find that the decline occurred precisely at the expense of private households. The decline in production by households in January-May is 3,7\% compared to the level of January-May 2019, while the level of production by enterprises has remained almost unchanged and amounted to $99,5 \%$ of the level of the same period last year.

The situation with a drop in production and sales precisely at the expense of private households of the population can be explained by the lesser accessibility to sales markets through quarantine restrictions. While enterprises focus mainly on the supply of products to 
retail chains and operate on a contractual basis, the population sells their products in markets that have been closed for a long time due to the resistance to the spread of the pandemic. Lack of government assistance and limited ability to find new sales markets for themselves.

Tourism. According to the estimates of the Cabinet of Ministers of Ukraine, the losses of the tourism industry from COVID-19 amounted to 1,5 billion USD. Significant losses occur as a result of border closures, air and rail restrictions, and hotel closures.

The sphere of temporary accommodation and catering is going through hard times during the spread of the pandemic through COVID-19 and the introduction of quarantine measures. Due to quarantine restrictions, the sector suspended work, however, the actual spread of the pandemic and the risks associated with it damaged enterprises already in the first quarter of 2020. So, the number of enterprises that made a profit in the first quarter was only $28,3 \%$, although a year ago, in the first quarter of 2019 , the number of such enterprises was $70,2 \%$. Moreover, this indicator turned out to be the worst among all types of economic activity.

Concerns about changes in demand influenced capital investments in temporary accommodation and catering, as in the first quarter of this year they amounted to only $33,3 \%$ of the volume of the first quarter of 2019. Moreover, the greatest reduction in capital investment occurred where demand is not stable and depends on numerous factors. So, if capital investments in the activities of hotels and similar temporary accommodation facilities fell over the described period by $21,8 \%$, then the related group - the activity of accommodation facilities for the period of vacation and other temporary accommodation showed a decrease in capital investments by $80,3 \%$. This is due to the expectation of a drop-in demand and the possible risks due to the unpredictability of the pandemic.

Beauty industry. As for hairdressing salons, beauty salons, beauty and nail salons, they did not work during the strict quarantine measures to counter the pandemic. The closure of these establishments is due to the introduction of restrictions on the number of people and through close contact with the client.

The sphere of public catering. According to the estimates of various experts, losses can amount to $50 \%$ of revenue, personnel is lost. The forms of activity are being transformed in the direction of delivering orders to customers or taking-away.

Sphere of entertainment. The work of shopping and entertainment centers, cinemas, theaters, exhibition halls, concert activities stopped working - a significant number of people were left without work.

Event industry. Due to the ban on public events, it is impossible to hold conferences, business forums, religious meetings, concert tours, football championships, and the like. Already postponed to next year: Eurovision, Atlas Weekend, Euro 2020, Olympics 2020 and others. These are colossal losses for the industry. The recovery of the industry is also a question for quite a long time.

However, there are industries and areas of activity for which the COVID-19 pandemic has given a good start and revenue growth:

Online stores. Ordering through websites has increased by $80 \%$. In the early days of the introduction of quarantine, there was a shortage of goods in the following groups: essential goods (antiseptics, protective masks, toilet paper, paper towels) and food (water, cereals, oil, salt). 
Pharmacies. The sale of antiviral drugs increased 8 times. The greatest demand is for protective masks, alcohol, glycerin, antiseptics, antiviral and antipyretic drugs.

Media service. TV viewing grew by $27 \%$. Content consumption on news platforms has increased. Media group " $1+1$ " confirms the growth of demand for viewing the news «TCH», «ТСН-Тиждень». Content consumption also increased by $30 \%$ in the news platforms TCH.ua and UNIAN. MEGOGO statistics show that existing users began to watch Media service products longer and longer - by $22 \%$ on average.

Online education. The flow of requests for online training is growing. This is due to distance learning in schools and higher education institutions. In some regions, traffic to online education sites has tripled. [9]

Let us summarize the previous negative consequences due to the development of the COVID-19 pandemic for Ukraine:

- Decrease in the level of real GDP by $1,3 \%$, as well as the level of per capita income in Ukraine, which leads to uncertainty in the future.

- Drop in industrial production by $5,1 \%$.

- A decline in the volume of housing construction by $20 \%$, which is caused by low demand due to a decrease in effective demand from the population.

- A decrease in the number of passengers carried, which was $43,7 \%$ in the first five months of this year.

- The reduction in the total freight turnover for all types of transport reached $19,9 \%$.

- Losses in the tourism sector have brought the industry enterprises to the leaders in the number of unprofitable enterprises.

- Closing borders, restricting transport links and thereby complicating the export and import of goods and raw materials, doing business and attracting investments, which led to losses and a reduction in production.

- Services, hospitality, entertainment, theaters, cinemas, sporting events, retail trade in non-food products were most affected.

- An increase in the number of unemployed, as a result of a decrease in the production of goods and services, as well as negative expectations of business.

Measures introduced by the Ukrainian government to mitigate the economic crisis and support the country's economy:

- For entrepreneurs who work independently without hired workers were exempted from a single social contribution until the end of quarantine.

- For small and medium-sized businesses, inspections and penalties for the period of quarantine were canceled.

In fact, the COVID-19 pandemic requires a change in the way we do business, and this raises the question of what business should be like during a pandemic. What advice can be given to entrepreneurs, business owners and management personnel in this situation?

Firstly, it is necessary to achieve and actively participate in launching a program to stimulate demand for domestically produced products, the most important thing for companies to stay on the same wavelength with their consumers and their needs, focus on market needs and orient consumers towards goods and services of a local manufacturer. In conditions when incomes and demand for products and enterprises are reduced in investment opportunities, re-equipment, and also lose "safety margin", imports from countries where manufacturers 
received significant financial support from governments begin to occupy an increasing market share.

Secondly, you need to focus not only on sales, but also on your reputation. After all, the client is too sensitive to any irritants, especially during crises, and therefore reacts very much to the actions of companies that try to work in violation of quarantine rules. Since the introduction of quarantine measures, there have been several scandals due to violation of the quarantine rules by business, and they have received considerable attention despite the existence of other numerous and complex problems in the country.

Thirdly, a set of measures should be immediately developed and implemented in order to maintain production and sales volumes for those companies that have now significantly increased profits. After the quarantine is lifted, reducing the impact of the pandemic, their activities will become less profitable due to the fact that the consumer will be saturated with their products and, perhaps, will not require it for a long time. Such enterprises must develop plans to diversify production, search for new areas and accumulate sufficient funds to carry out re-equipment, marketing campaigns and the like.

Fourth, it is necessary to ensure further communication of companies with their customers, especially in those industries where today there is a significant decline in production and sales. Businesses should try to maximize the availability of a product or service where the customer requires it in a pandemic, imposed quarantine restrictions. And also, to clearly understand the size of the deferred demand, understand the time and opportunities when it can be satisfied. In conditions when market needs change dramatically under the influence of external factors, it is necessary to constantly monitor these changes and respond accordingly, in addition, make plans and develop strategies in accordance with new potential challenges.

Fifth, those companies that are socially responsible will be able to more easily retain their customers. An example is those companies that resort to charity in an epidemic (Nova Poshta, Privatbank, Epicenter, Silpo and others). Using charities as PR, they will strengthen the interaction with those clients and consumers who will attract new ones with them today. Considering the pressing needs of society, which are easy to detect and relatively simple to meet, you can quickly and effectively improve your reputation and build trust.

Sixth, valuable personnel should be retained during the suspension or production cuts. Many enterprises spend considerable resources on training employees and improving their qualifications and attempts to save on the wage bill today can lead to a rapid increase in costs in future periods. In addition, due to the growth of the market and the need to increase production, it is quite possible that there is a shortage of personnel, and enterprises that have lost their employees during the pandemic will not be able to respond in time to the growth in demand and will lose market share.

Seventh, it is necessary to engage in forecasting the action of the market in the period of the end of the pandemic, to plan the return of the enterprise to the previous volumes of production or provision of services. You should also consider possible changes in the market, as well as the consequences of the pandemic. It is worth remembering that the end of the pandemic does not mean the return of size and structure to the indicators of 2019, so you should be prepared for new conditions.

Of course, this list cannot be considered exhaustive or a panacea for the COVID-19 pandemic. However, timely response and targeted action will reduce the negative impact of the COVID-19 pandemic, prevent a decline in business activity, create conditions for the 
development of Ukrainian manufacturers and reduce the scale of the consequences of the crisis caused by the COVID-19 pandemic.

\section{Conclusions}

The government's response to challenges should be multi-vector. It is not enough just to help businesses weather a downturn in production and profitability, to prevent a wave of bankruptcy due to financial difficulties as a result of the pandemic. The country's authorities constantly analyze changes in the rates of production and sale of goods and services, provide support to the most vulnerable sectors and those sectors that form the basis of the country's economy. Due to the overlap of factors of reduction and demand, and supply for various reasons, possible gaps in meeting the needs of manufacturing enterprises in raw materials and equipment, the emergence of scarce materials, etc. reduce production and thus the market will be unable to meet demand. Since the market in a free economy is not able to independently cope with such situations promptly, the task of the state is to provide critical production segments with the necessary raw materials, etc. by stimulating production, building stocks, providing soft loans and direct support.

Constant analysis of the situation on markets and production, quick response to identified problems, as well as forecasting the emergence of new problems are becoming the most important tasks of state regulation. Given the interdependence of various sectors of the economy and the specific needs of each of them, it is important to correctly assess the challenges and predict the possible complex consequences of the pandemic impact. Government assistance is extremely important when new risks appear on the market, the response to which is difficult due to the lack of practice and experience.

At the same time, the authorities should avoid increasing taxes and expanding the tax base, complicating licensing conditions, significant changes in accounting, and the like. Since enterprises in the context of the growing economic crisis and pandemic are forced to respond to complex and often new challenges for themselves, complications of work through changes in legislation and additional tax pressure significantly increase risks and make it impossible to quickly respond to changes in demand and production conditions. Compensating for budget losses at the expense of business is a very dangerous activity and can provoke an even greater reduction in revenues.

\section{REFERENCES}

[1] The World Bank (2020). Retrieved from: https://www.worldbank.org/en/news/feature/2020/06/08/the-global-economic-outlook-during-the -covid-19-pandemic-a-changed-world (accessed 5 June 2020).

[2] Xinhua News (2020). Retrieved from:_http://russian.news.cn/2020-07/09/c_139200528.htm (accessed 5 June 2020).

[3] CNN Business (2020). Retrieved from: https://edition.cnn.com/2020/04/16/economy/china-economy-gdp/index.html (accessed 5 June 2020).

[4] International Monetary Fund (2020). Retrieved from: https://www.imf.org/en/Publications/WEO/Issues/2020/06/24/WEOUpdateJune2020 (accessed 5 June 2020).

[5] Financial Times (2020). Retrieved from: https://www.ft.com/content/454b7bb2-6405-11ea-a6cd-df28cc3c6a68 (accessed 5 June 2020). 
[6] State Statistics Service (2020). Retrieved from: http://www.ukrstat.gov.ua/ (accessed 5 June 2020).

[7] Ministry of Economic Development, Trade and Agriculture of Ukraine (2020). Retrieved from: https://www.me.gov.ua/?lang=uk-UA (accessed 5 June 2020).

[8] Economic truth(2020).

Retrieved from:https://www.epravda.com.ua/publications/2020/03/19/658296/\#17 (accessed 5 June 2020).

[9] Quarantine because of COVID-19. How to protect the economy and help Ukrainians?. (2020). Retrieved from: https://www.radiosvoboda.org/a/30505059.html (accessed 5 June 2020).

[10] Impact of COVID-19 on the world economy and Ukraine's foreign trade. (2020). Retrieved from: https://voxukraine.org/uk/vpliv-covid-19-na-svitovu-ekonomiku-ta-zovnishnyu-torgivlyu-ukrayi ni/ (accessed 5 June 2020).

[11] Global economy could shrink by almost $1 \%$ in 2020 due to COVID-19 pandemic: United Nations. (2020).

Retrieved

from: https://economictimes.indiatimes.com/https://economictimes.indiatimes.com/news/international/ business/global-economy-could-shrink-by-almost-1-in-2020-due-to-covid-19-pandemic-united-n ations/articleshow/74943235.cms?utm_source= _medium=text\&utm_campaign=cppst (accessed 5 June 2020).

[12] Projected Impact of COVID-19 on Ukraine's Economy (2020). Retrieved from: https://www.wilsoncenter.org/blog-post/projected-impact-covid-19-ukraines-economy (accessed 5 June 2020).

[13] Ukrainian Institute of the Future (2020). Retrieved from: https://www.uifuture.org/ (accessed 5 June 2020). 